\title{
Application of Mesoporous Materials as Fining Agents for Pedro Ximénez Wines
}

\author{
Georgiana-Diana Dumitriu ${ }^{1}$, Nieves López de Lerma ${ }^{2 *}$,Valeriu V. Cotea ${ }^{1}$ and Rafael A. Peinado ${ }^{2}$ \\ ${ }^{1}$ Department of Viticulture and Oenology, Faculty of Horticulture, University of Agricultural Sciences and \\ Veterinary Medicine "Ion Ionescu de la Brad" Iasi, Romania \\ ${ }^{2}$ Department of Agricultural Chemistry, Building Marie Curie, Campus of Rabanales, Agrifood Campus of \\ International Excellence ceiA3, University of Córdoba, Spain \\ Email: b92lolem@uco.es
}

\begin{abstract}
In recent years, nanotechnology has advanced rapidly worldwide, providing significant benefits to an increasing number of products from different areas, including energy and environment, textiles, transportation, information, electronics, construction, biotechnology, health, agriculture, food, and beverage. Wine proteins may become insoluble and precipitate which is an important problem in wine stability. The aim of this paper is to study the usefulness of mesoporous materials (MCM-41, SBA-15 and KIT-6) to remove excess proteins of white wines (Vitis vinifera cv. Pedro Ximenez) and its influence on different physical-chemical parameters, phenolic content, and antioxidant activity. Results had showed that nanomaterials MCM-41 and SBA-15. reduced significantly the nephelometric turbidity units, which were related with protein concentration, whereas KIT-6 had a low influence in the final protein content. The total polyphenols content is scarcely affected by the treatment although antioxidant activity is reduced in wines treated with SBA-15. According to the set of results, SBA-15 and MCM-41 seem to be the most effective nanomaterials although the last one slightly decreases the antioxidant activity.
\end{abstract}

Keywords: Fining agent, nanomaterials, Pedro Ximénez, protein haze, turbidity.

\section{Introduction}

During the last two decades, nanostructured materials offer exciting opportunities for a large number of applications [1-4]. Among these nanomaterials, mesostructured materials have been intensively investigated. Mesoporous materials are defined by IUPAC as the materials with pore sizes between 2 and $50 \mathrm{~nm}$. Mesoporous structures are presented by a wide class of substances including silica, metal oxides, metal hydroxides, metal salts, carbon structures, hybrid materials, organic structures, and many others. Mesoporous materials are highly attractive for a wide variety of applications in technical sciences such as catalysis [5], electronics [6], photocatalytic hydrogen production [7], solar cells [8], and battery components [9].

A family of ordered mesoporous silica molecular sieves known as M41S assures a bright future due to their properties: a well-defined pore size between 2-20 nm, an extraordinary high specific surface up to $1000 \mathrm{~m} 2 / \mathrm{g}$ and distinct adsorption properties due to their pore volume around $0.9 \mathrm{~cm} 3 / \mathrm{g}$ [10].

SBA-15 is by far the largest pore-size mesoporous material. It has highly ordered hexagonally arranged mesochannels, with thick walls, adjustable pore size from 3 to $30 \mathrm{~nm}$, high hydrothermal, and thermal stability. Also, they are ideal for size and shape exclusion separation of polyphenols, proteins and other small biological molecules [11].

In literature, it was reported that the synthesis of other mesoporous materials with larger pores, KIT6 , with Ia3d cubic type structure and a network of interconnected channels. Siliceous material has numerous applications in adsorption and catalysis, thanks to a unique 3-D structures [12].

Wine clarity particularly, white wines, is significant to most consumers and is also one of the attribute that is easily affected by improper shipping and storage conditions. An important stage in winemaking is the addition of fining agents to adsorb undesirable products and to aid wine stability. Wine proteins may become insoluble and precipitate which is an important problem in wine stability. This fact is 
known as protein haze and it generally occurs when the wine is stored at a high temperature or when it is enriched with tannins from cork or wood. Higher protein levels are typical in overripe grapes, grapes sourced from warmer regions and grapes harvest mechanically. Skin contact will typically increase protein concentration [13]. Common fining agents include bentonite, egg white, carbon, gelatine, and polyvinylpolypyrrolidone (PVPP). In white wines the protein are eliminated with a bentonite treatment [14]. It also adsorbs positively charged molecules, such as anthocyanins and other compounds. With the help of gravity, particles sink to the bottom of the container.

Winemakers try to introduce of alternatives with fewer drawbacks than the current practice. In this context, the aim of this paper is to study the usefulness of mesoporous materials (MCM-41, SBA-15 and KIT-6) to remove excess proteins of white wines (Vitis vinifera cv. Pedro Ximenez) and its influence on different physical-chemical parameters, phenolic content, and antioxidant activity.

\section{$2 \quad$ Materials and Methods}

\subsection{Nanomaterials}

All nanomaterials (KIT-6, MCM-41 and SBA-15) were purchased from ACS Material (Advanced Chemicals Supplier), LLC 18 Vernon Street Medford, USA.

\subsection{Winemaking Process}

Pedro Ximénez grape variety (V. vinifera) harvested in 2014 in the Montilla-Moriles winemaking region (Córdoba, Spain) was crushed and the must obtained was macerated at $4^{\circ} \mathrm{C}$ during 12 hours. The must was inoculated with selected yeast and fermented at $20^{\circ} \mathrm{C}$. The resulting wine was spontaneous fining.

$2 \mathrm{~g} / \mathrm{L}$ of three types of nanomaterials (Table 1, Fig. 1) were added at three samples of wine. The solutions were stirred $24 \mathrm{~h}$ in hermetic glass flask. After that, $15 \mathrm{~g} / \mathrm{HL}$ gelatine was added. Also, a control was carried out without nanomaterials. The resulting samples were centrifuged at $5000 \mathrm{rpm}$ and $4{ }^{\circ} \mathrm{C}$ for 10 minutes.

Table 1. Types and characteristics of nanomaterials

\begin{tabular}{l|l|l|l}
\hline Nanomaterial & KIT-6 & MCM-41 & SBA-15 \\
\hline SSA (m2/g) & $600-800$ & $850-850$ & 600 \\
\hline PD $(\mathrm{nm})$ & $8-10$ & $3.4-5.0$ & $7-10$ \\
\hline PS $(\mu \mathrm{m})$ & $10-100$ & $100-1000$ & $1-2$ \\
\hline
\end{tabular}

SSA: Specific Surface Area, PD: Pore Diameter, PS: Particle Size
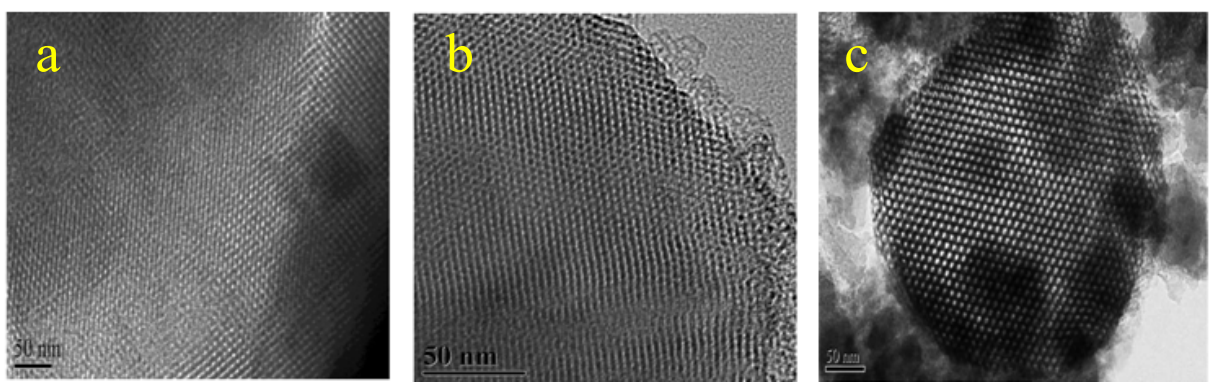

Figure 1. Transmission electron microscopy images of nanomaterials: KIT-6(a), MCM-41(b) and SBA-15(c) 


\section{$2.3 \quad$ Turbidity}

Turbidity was measured with a nephelometer (HANNA instruments, HI 93703, Woonsocket, RI, USA C). Turbidity determinations were done at room temperature; results are expressed in nephelometric turbidity units (NTU).

\subsection{General Enological Determinations}

$\mathrm{pH}$, titratable acidity, and volatile acidity were determined by the official European Union methods [15]. Ethanol content was quantified by oxidation with dichromate according to Crowell and Ough [16].

\subsection{Absorbance Measurements}

Prior to analyses the samples were filtered through a HA-0.45 $\mu \mathrm{m}$ paper (Millipore, Milford, MA). Browning index was determined by measuring the absorbance at 420 . Wine color was defined by the CIE Lch space in which there are three axes: $h^{*}$ (hue), $L^{*}$ (lightness) and $c^{*}$ (chroma or saturation). Total polyphenols index (TPI) was determined by measuring the absorbance at $280 \mathrm{~nm}$. All determinations were carried out in a spectrophotometer Perkin Elmer Lambda 25.

\subsection{Total Antioxidant Activity (TAA)}

Antioxidant activity was measured with the blue/green chromophore ABTS $\bullet+$ method described by Re et al. [17]. The ABTS $\bullet+$ was produced by oxidation of $7 \mathrm{mM}$ ABTS with $2.45 \mathrm{mM}$ potassium persulphate in conditions of darkness for 12-16 hours. The resulting ABTS $\bullet+$ solution was diluted in 20 $\mathrm{mM}$ phosphate buffer at $\mathrm{pH} 7.4$ to obtain an absorbance at $734 \mathrm{~nm}$ of 0.7 . A volume equal to or greater than $900 \mu \mathrm{L}$ of this test mixture was reacted with a volume equal to or less than $100 \mu \mathrm{L}$ of wine samples, previously filtered through HA- $0.45 \mu \mathrm{m}$ papers (Millipore, Milford, MA), for $6 \mathrm{~min}$. After this time, the absorbance at $734 \mathrm{~nm}$ of the reaction mixture was measured. Antioxidant activity was measured in terms of the proportion of ABTS $\bullet+$ inhibited: \% inhibition $=($ A734 blank - A734 sample $)$ x 100/ A734 blank. This percentage of inhibition should fall in the range $20-80 \%$.

\section{$2.7 \quad$ Statistical Treatment}

All analyses were made for triplicate and a homogeneous group's analysis was made by means of the statistical package Statgraphics Centurion XVI from StatPoint Technologies, Inc. (Warrenton, VI, USA) to study if there were significant differences among the samples in the determined parameters.

\section{$3 \quad$ Results and Discussion}

\subsection{Influence of the Fining Agents on Enological Parameters}

Protein instability in white wines causes clarity problems known as protein case. The white wine is considered to be stable if the resulting turbidity, or haze, is less than 1.1 nephelometric turbidity units (NTU) [17]. Results showed that all nanomaterials increased the limpidity of wines although only the treated wines with SBA-15 showed an admissible NTU value (Fig. 2).

The analytical parameters of control wine were habitual of white wines (Table 2). Ethanol content was $16.36 \pm 0.02$ in all wines. Enological parameters of treated wines showed a slight decrease when compared to control wine. This may be due to the interaction of nanomaterials with the components of wine or to the displacement of the chemical balances by the change of $\mathrm{pH}$. Anyway, nanomaterials contribute to reduce both the volatile acidity and the browning index, parameters which are related to analytical quality of wine.

Previous studies on red wines [18] have shown that small variations of total acidity are present in samples treated with clinoptilolite and KIT-6. Also, the volatile acidity increased in Merlot samples treated with ALMCM-41 and clinoptilolite and decreased in Cabernet wines treated with AlMCM-41. 


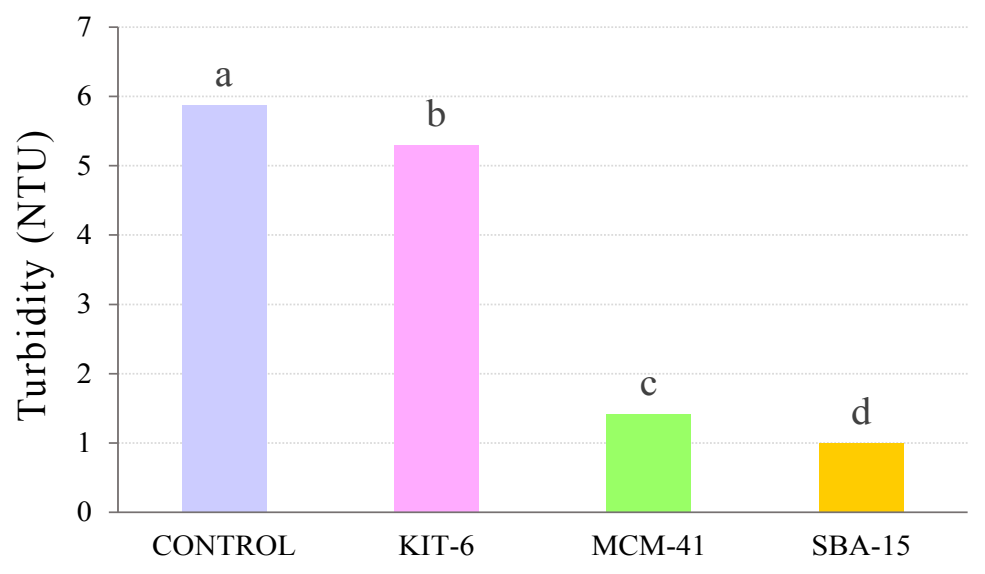

Figure 2. Turbidity of wines after treatment, expressed as nephelometric turbidity units (NTU). Different letters indicate significant differences at $95 \%$ of confidence level

Table 2. Enological parameters of wines after treatments

\begin{tabular}{l|l|l|l|l}
\hline & $\mathrm{pH}$ & $\mathrm{TA}$ & $\mathrm{VA}$ & $\mathrm{BI}$ \\
\hline Control & $3.36 \pm 0.04$ & $5.00 \pm 0.04$ & $0.5 \pm 0.0$ & $0.166 \pm 0.003$ \\
\hline KIT-6 & $3.31 \pm 0.02$ & $5.00 \pm 0.04$ & $0.4 \pm 0.0$ & $0.155 \pm 0.005$ \\
\hline MCM-41 & $3.29 \pm 0.01$ & $4.83 \pm 0.04$ & $0.4 \pm 0.0$ & $0.161 \pm 0.007$ \\
\hline SBA-15 & $3.28 \pm 0.01$ & $4.88 \pm 0.01$ & $0.4 \pm 0.0$ & $0.168 \pm 0.006$ \\
\hline HGA & a b b b & a a b b & a b b b & a b ab a \\
\hline
\end{tabular}

Data expressed as mean \pm standard deviation. TA: titratable acidity (g tartaric acid/L), VA: volatile acidity (g acetic acid/L), BI: browning index; HGA: homogenous groups analysis, different letters indicate significant differences at $95 \%$ of confidence level

\subsection{Influence of the Fining Agents on Color Parameters}

Fig. 3 shows the color properties $\mathrm{h}^{*}$ (hue), $\mathrm{c}^{*}$ (chroma) and $\mathrm{L}^{*}$ (lightness) for the wine samples. All wines had a yellowish hue - the hue values can range from $0^{\circ}$ (red), through $90^{\circ}$ (yellow), $180^{\circ}$ (green), $270^{\circ}$ (blue) and back to $360^{\circ}$ or $0^{\circ}$ - but the control and treated with SBA-15 wines showed a more orange-yellow hue that treated wines with KIT-6 and MCM-41. These results are according to browning index values.

The property chroma or saturation is related with purity color (bandwidth) and it can range from 0 , which is completely unsaturated (very broad set of wavelengths), to 100 for pure color (very limited set of wavelengths). All wine samples showed very little saturated colors, being the treated wines those with the lowest values. It seems that the purity color is directly related to the browning.

Finally, the property lightness shows clarity or darkness color (pigment concentration). It can range from 0, which has no lightness (pigment concentration very high, i.e. absolute black), to 100, which is maximum lightness (pigment concentration very low, i.e. absolute white). All wine samples had colors very lightness, their $\mathrm{L}$ values were above 95 , which is probably related to maceration process. Moreover, the treated wines showed lower pigment concentration that control wine, which may be due to the interaction of nanomaterials with the pigments of wine. Some author argued [19] that the clarity (L) values of wine sample treated with different amounts of KIT-6 mesoporous material remained similar for all probes analyzed. 

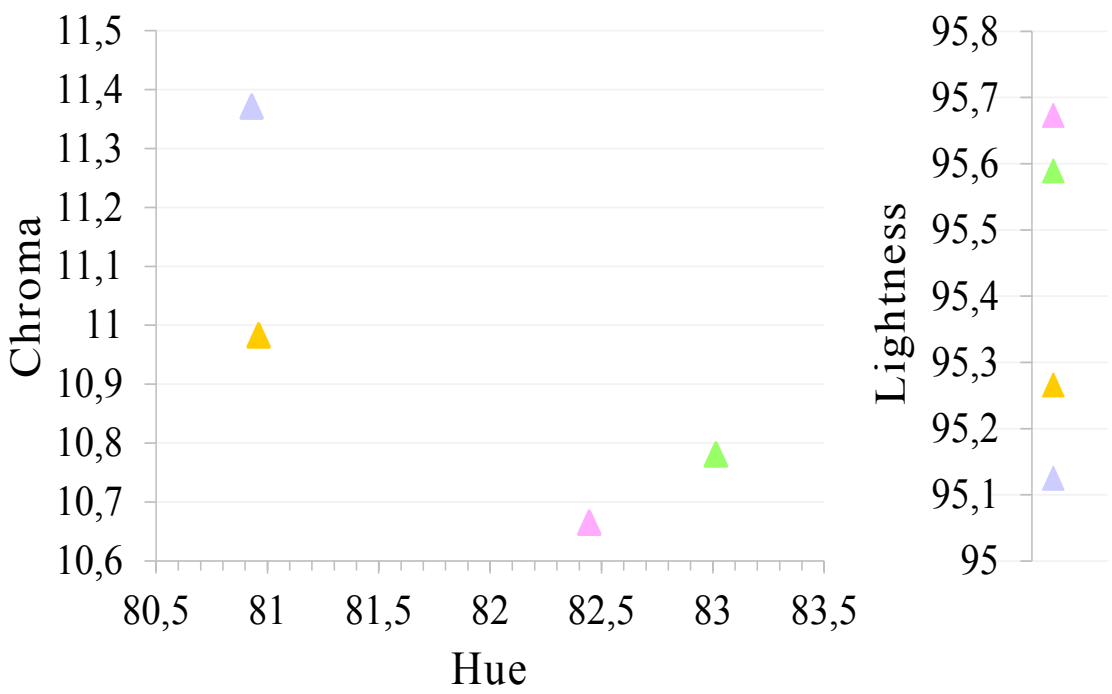

Figure 3. Color properties hue, chroma and lightness of control wine (blue) and wines treated with KIT-6 (pink), MCM-41 (green) and SBA-15 (yellow)

\subsection{Influence of the Fining Agents on TPI and TAA}

Relative to total polyphenols index (Fig. 4), the nanomaterials did not significantly modify the phenolic content respect to control wine. Slight changes observed were according to browning index and lightness values and they resulted in significantly different antioxidant activity values in treated wines with KIT6 and SBA-15. Modification of TAA was inversely proportional to modification of TPI. This result put in evidence that the antioxidant activity response of polyphenols is more markedly influenced by their chemical structure than by their total concentration [18]. In addition, there may be a synergistic and antagonistic antioxidant interaction between phenolic compounds [19].

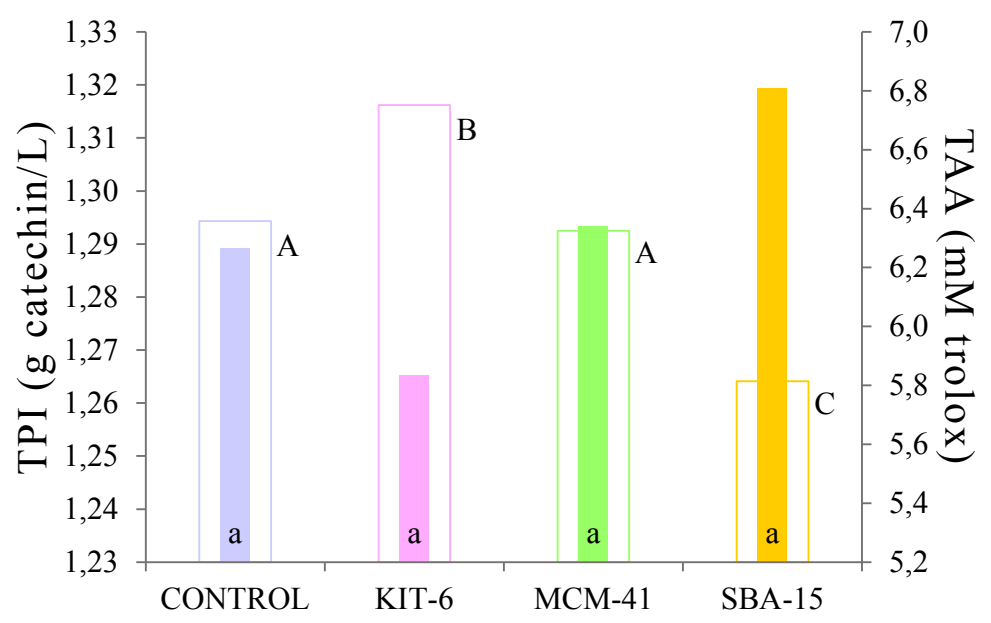

Figure 4. Total polyphenols index (TPI), expressed as grams of catechin per liter (full bars), and total antioxidant activity (TAA), expressed as millimolar of trolox (empty bars), of wines after treatment. Different small letters indicate significant differences at $95 \%$ of confidence level in TPI values. Different capital letters indicate significant differences at $95 \%$ of confidence level in TAA values 


\section{Conclusions}

Results had showed that nanomaterials reduce the NTU value, which are related with protein concentration, without adversely modifying the parameters measured. Enological parameters of treated wines showed a slight decrease when compared to control wine. Mesoporous materials contribute to reducing the volatile acidity and the browning index, parameters which are related to analytical quality of wines. Nanomaterial SBA-15 was the most effective although it slightly decreased the antioxidant activity.

It is expected that nanotechnology applications will bring a range of advantage to the wine domain with the aim of providing better quality, stabilization, conservation and safety

Acknowledgments. This paper was carried out under the frame of OIV Research Grant. We are also grateful to the Oenological Research Center-Romanian Academy, Iasi Branch and to the Vitenol Research Group, University of Cordoba.

\section{References}

1. J. Gao and B. Xu, "Applications of nanomaterials inside cells," Nano Today, vol. 4, pp. 37-51, 2009.

2. M. Geszke-Moritz and M. Moritz, "Quantum dots as versatile probes in medical sciences: synthesis, modification and properties," Materials Science and Engineering C, vol. 33, pp. 1008-1021, 2013.

3. M. Moritz and M. Geszke-Moritz, "The newest achievements in synthesis, immobilization and practical applications of antibacterial nanoparticles," Materials Science and Engineering, vol. 228, pp. 596-613, 2013.

4. X. Ren, C. Chen, M. Nagatsu, X. Wang, "Carbon nanotubes as adsorbents in environmental pollution management": a review, Chemical Engineering Journal, vol. 170, pp. 395-410, 2011.

5. C. Perego and R. Millini, "Porous materials in catalysis: challenges for mesoporous materials," Chemical Society Reviews, vol. 42, pp. 3956-3976, 2013.

6. I. E. Rauda, L. C. Saldarriaga-Lopez, B. A. Helms, L. T. Schelhas, D. Membreno, D. J. Milliron, S. H. Tolbert, "Nanoporous semiconductors synthesized through polymer templating of ligand-stripped CdSe nanocrystals," Advanced Materials, vol. 25, pp. 1315-1322, 2013.

7. S. Onsuratoom, S. Chavadej, T. Sreethawong, "Hydrogen production from water splitting under UV light irradiation over Ag-loaded mesoporous-assembled $\mathrm{TiO} 2-\mathrm{ZrO} 2$ mixed oxide nanocrystal photocatalysts," International Journal of Hydrogen Energy, vol. 36, pp. 5246-5261, 2011.

8. P. Zhu, M. V. Reddy, Y. Wu, S. Peng, S. Yang, A. S. Nair, K. P. Loh, B. V. R. Chowdari, S. Ramakrishna, "Mesoporous $\mathrm{SnO} 2$ agglomerates with hierarchical structures as an efficient dual-functional material for dyesensitized solar cells," Chemical Communications, 2012, vol. 48, pp. 10865-10867, 2012.

9. J. Park, W. G. Moon, G. P. Kim, I. Nam, S. Park, Y. Kim, J. Yi, "Three-dimensional aligned mesoporous carbon nanotubes filled with $\mathrm{Co} 3 \mathrm{O} 4$ nanoparticles for Li-ion battery anode applications," Electrochimica Acta, vol.105, pp. 110-114, 2013.

10.C. Kresge, M. E. Leonowicz, W. J. Roth, J. C. Vartuli, J. S. Beck, "Ordered mesoporous molecular sieves synthesized by a liquid-crystal template mechanism," Nature, vol. 359, pp. 710-712, 1992.

11.D. Y. Zhao, J. L. Feng, Q. S. Huo, N. Melosh, G. H. Fredrikson, B. F. Chmelka, "Stucky triblock copolymer syntheses of mesoporous silica with periodic 50 to 300 angstrom pores," Science, vol. 279, pp. 548-552, 1998.

12.L. Xiaoying, T. Bozhi, Y. Chengzhong, G. Feng, X. Songhai, T. Bo, C. Renchao, P. Lian-Miao, Z. Dongyuan, "Room-temperature synthesis in acidic media of large-pore three-dimensional bicontinuous mesoporous silica with Ia3d symmetry," Angewandte Chemie, vol. 114, pp. 4032-4034, 2002.

13.J. Moreno and R. A. Peinado, Enological Chemistry. Academic Press. Elsevier, 2012.

14.M. R. Sarmentoa, J. C. Oliveirab, M. Slatnerc, R. B. Boultond, "Influence of intrinsic factors on conventional wine protein stability test," Food Control, vol. 11, no. 6, pp. 423-432, 2000.

15.CEE. Diario oficial de la comunidad Europea L-272. Madrid: Mundi-Prensa, 1990.

16.E. A. Crowell, C. S. Ough, "A modified procedure for alcohol determination by dichromate oxidation," American Journal of Enology and Viticulture, vol. 30, pp. 61-63, 1979. 
17.R. Re, A. Pellegrini, A. Pannala, M. Yang, C. Rice-Evans, "Antioxidant activity applying an improved ABTS radical cation decolorization assay," Free Radical Biology and Medicine, vol. 26, pp. 1231-1237, 1999.

18.N. López de Lerma, J. Peinado, R. A. Peinado, "In vitro and in vivo antioxidant activity of musts and skin extracts from off-vine dried Vitis vinifera cv. "Tempranillo" grapes," Journal of Functional Foods, vol. 5, 914-922, 2013.

19.B. L. Freeman, D. L. Eggett, T. L. Parker, "Synergistic and antagonistic interactions of phenolic compounds found in navel oranges," Journal of Food Science, vol. 75, no. 6, 570-576, 2010 